
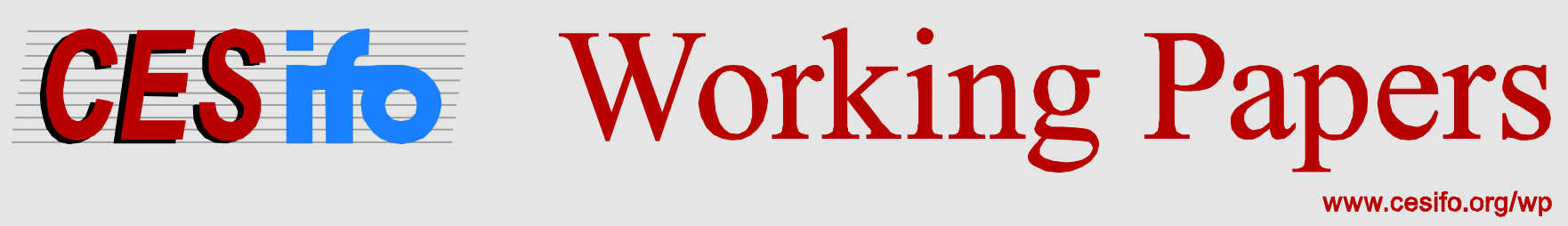

\title{
Cooperative and Non-Cooperative Equilibrium Consumption Taxes in the Presence of Cross-Border Pollution
}

\author{
Michael S. Michael \\ Panos Hatzipanayotou
}

CESIFO WORKING PAPER NO. 4501

CATEgory 1: Public FinANCE

NOVEMBER 2013
An electronic version of the paper may be downloaded
- from the SSRN website: Www.SSRN.com
- from the RePEc website: Www.RePEc.org
- from the CESifo website: www.CESifo-group.org/wp

\section{CESifo}




\title{
Cooperative and Non-Cooperative Equilibrium Consumption Taxes in the Presence of Cross-Border Pollution
}

\begin{abstract}
We consider a two small open economies model with cross-border pollution that is generated from consumption. Within this framework we examine i) the non-cooperative equilibrium consumption taxes and compare them to when pollution is only local, ii) the cooperative equilibrium consumption taxes and we compare them to the non-cooperative tax rates, and iii) cases where cooperative taxes are different between countries. In this framework, tax harmonization may not be the optimal policy if, for example, pollution per unit of consumption differ between countries. Many results of the paper depend on the relationship in consumption (i.e., complementarity or substitutability) between pollution and the polluting good.
\end{abstract}

JEL-Code: H210, H230.

Keywords: consumption taxes, cross-border pollution, non-cooperative and cooperative equilibrium.

\author{
Michael S. Michael \\ Department of Economics \\ University of Cyprus \\ P.O. Box 20537 \\ Cyprus - 1678, Nicosia \\ m.s.michael@ucy.ac.cy
}

\author{
Panos Hatzipanayotou \\ Department of International and European \\ Economic Studies / Athens University of \\ Economics and Business \\ 76, Patission str. \\ Greece - Athens 10434 \\ hatzip@aueb.gr
}

November 25, 2013

We thank Karl Zimmermann, and participants in the 14th Annual PET Conference, the 15th Annual ETSG Conference, and the 69th Annual IIPF Congress, for their constructive comments and suggestions. The authors graciously acknowledge the co-funding of this research by the European Social Fund (ESF) and the Greek NSRF-Research Funding Program: THALIS. The authors are solely responsible for possible shortcomings of the paper. 


\section{Introduction}

Two, among other, key policy issues that stand out in today's global economy are the following. First, is the concern for growing environmental degradation due to cross-border pollution resulting from polluting production and consumption activities. In this regard, on the one hand, a voluminous literature addresses the question of production generated cross-border pollution, proposing the use and examining the economic implications of environmental policies such as emissions taxes, source or sector specific emissions standards and emissions permits. On the other hand, a much smaller literature addresses the problem of consumption generated cross-border pollution. Moreover, hardly ever emissions control policies such as the ones noted above, are used for controlling cross-border pollution when its source is the consumption activity. More often than not, however, consumption taxes are the policy instrument to which policy makers resort in order to control this international externality. The second issue at hand is that of the need of harmonizing indirect taxes, e.g., consumption, production and trade taxes, in the process of deepening economic integration and cooperation among countries. For example, within the EU, consumption tax harmonization has been recommended both in theory and policy forums, as the optimal policy choice to acquiring the full benefits of economic integration.

With this background, several still unexplored by the relevant literature pivotal questions can be raised. For example, what is the level of optimal, non-cooperative and cooperative, consumption taxes in the presence of consumption generated cross-border pollution? How do these Nash and cooperative taxes compare between them, and how do they compare when pollution is only local? Can cooperative consumption taxes differ between countries? And, least but not last, is consumption tax harmonization between countries optimal in the presence of consumption generated cross-border pollution? The paper contributes to the relevant literature by offering some analytical insights to these issues.

The public finance literature has extensively examined the welfare and tax revenue implications of consumption taxation, e.g., Diamond and Mir- 
rlees (1971), Browning (1985), as well as other related issues, e.g., the implications of moving consumption taxes on different commodities towards uniformity, e.g., Atkinson and Stiglitz (1976), Hatta (1977) and (1986). Another strand of the literature raises the issue of reforming an open economy's structure of indirect taxes away from the more distortive trade taxes, i.e., import tariffs and export taxes, and towards less distortive domestic taxes such as consumption taxes. This has been motivated by the quest of countries to improve welfare and maintain or even raise government tax revenues in the process of trade liberalization during the recent decades, which resulted to large reductions in trade taxes, e.g., Michael et al. (1993), Abe (1995), Keen and Ligthart (2002), Lahiri and Nasim (2005), Emran and Stiglitz (2005) and Boadway and Sato (2009), Haibara (2012). ${ }^{1}$

Recently, in many, particularly developed countries, viable concerns have been raised about the negative environmental implications of the expanding global economic activity. ${ }^{2}$ In light of these concerns, various environmental policy instruments such as emissions taxes or emissions permits have been implemented in order to restrict the environmentally "damaging" activities and to promote environmentally "friendly" ones. In this vein, the use of consumption taxes has been proposed as a viable alternative policy measure to environmental taxes in order to contain environmental damages. On the one hand, this policy has been promoted following the realization that environmental tax revenues as share of the GDP are relatively low, even among rich-developed countries with long tradition in the use of environmental taxes, e.g., the EU. ${ }^{3}$ On the other hand, with consumption expenditures

\footnotetext{
${ }^{1}$ Another direction of a theoretical as well as policy debate is whether taxation of final commodities should follow the so-called "destination" or "origin" principle e.g. see among others Georgakopoulos and Hitiris (1992), Bovenberg (1994), Keen and Lahiri 1998, Karakosta et al. (forthcoming). This debate over the two taxation principles has become even more prevalent in the recent decades with the expansion of regional economic integration.

${ }^{2}$ For example, a frequently raised theoretical and policy related question has been "Is free trade good for the environment?", e.g., see Antweiler et al. (2001).

${ }^{3}$ For example, Stamatova and Steurer (2011) report that in the EU-27 environmental tax revenues as share of the GDP was 2,4 in 2010. In only four countries environmental tax revenues as share of the GDP exceeded 5 percent, namely, Bulgaria, Malta, Slovenia and the Netherlands.
} 
by households and non-profit organizations servicing households representing approximately 58 percent of the GDP in the EU-27 in 2011, the use of consumption taxes, for environmental purposes, pose an advantage over direct pollution taxes of a much larger taxation base. ${ }^{4}$ Equally important it is argued that consumption taxes may require less complex bureaucratic structures and institutional innovation, and thus, can be easier to implement compared to emissions taxes.

On the grounds of such considerations, a small but growing literature considers the use of consumption taxes as an alternative mean to pure environmental policy instruments such as emission taxes and emissions permits, when consumption entails the creation of pollution emissions. This literature, by and large, considers the welfare, tax revenue and environmental implications of reforms in trade, consumption and or production taxes, in the presence of pollution, e.g., Copeland (1994), Beghin et al. (1997), TurunenRed and Woodland (2004), Kayalica and Kayalica (2005), Haibara and Ohta (2011), Michael and Hatzipanayotou (2013).

In this paper, we construct a model of two small open economies with cross-border pollution generated from consumption. Consumption taxes are levied by the government in each country. In section 2 we describe the model. In section 3 we derive the Nash-equilibrium consumptions taxes and we compare them to the case where consumption pollution is local. Then we examine how changes in the rates of pollution per unit of consumption, or of cross-border pollution affect these Nash consumption taxes. In section 5 , we derive the cooperative equilibrium consumption taxes and we compare them to the Nash tax rates. Finally we identify conditions under which the cooperative consumption taxes in the two countries can be the same. In section 6 we provide the concluding remarks.

\footnotetext{
${ }^{4}$ On such grounds Albrecht (2006) proposes: " .... A green tax reform could therefore also be based on existing consumption taxes instead of direct pollution taxes ..." , p.94
} 


\section{The Model}

Consider a model with two small open economies, Home and Foreign, with a representative household, producing and consuming many traded goods. The world prices of these goods are fixed and, for simplicity, are set to be equal to one. In both countries, consumption of good 1 generates pollution which affects negatively household utility in both countries. A unit of consumption of good 1, in Home generates $\alpha$ units of pollution, and in Foreign it generates $\alpha^{*}$ units of pollution. Hereon, asterisks denote Foreign's variables. The consumption of the other goods does not generate pollution in either country. The governments in the two countries levy a consumption tax, $\tau$ and $\tau^{*}$ respectively, on the polluting good 1 . Thus, $p=1+\tau$ and $p^{*}=1+\tau^{*}$ denote, respectively, the consumer prices of the polluting good in the two countries. Let $E(1, p, r, u)$ be the minimum expenditure in Home required to achieve a given level of utility $u$ at consumer prices $(1, p)$ and level of overall pollution $r$, where 1 is the vector of consumer unit prices of all other (i.e., clean) goods. Its derivative with respect to $p$ (i.e., $E_{p}$ ), is the Hicksian demand function for the polluting good, and $E_{p p}<0 ;{ }^{5}$ its derivative with respect to $r$ (i.e., $E_{r}$ ), is positive and captures the households' marginal willingness to pay for reducing pollution, e.g., see Copeland (1994), and it is assumed that $E_{r r}>0 . E_{p r}$ denotes the relationship between the polluting good and pollution in consumption. If positive (negative), the two are complements (substitutes) in consumption. ${ }^{6}$ Finally, $E_{u}$, denotes the inverse of the marginal utility of income and for simplicity is set equal to one. Similarly, $E\left(1, p^{*}, r^{*}, u^{*}\right)$ denotes Foreign's minimum expenditure function. ${ }^{7}$ The production side of each country is represented by the GDP function, $R($.$) and$ $R^{*}($.$) , respectively. Production conditions bear no impact on the analysis to$

\footnotetext{
${ }^{5}$ All subscripts denote partial derivatives, e.g., $E_{p}=\partial E / \partial p$ and $E_{p p}=\partial E_{p} / \partial p$.

${ }^{6}$ Alternatively, it is to say that if $E_{p r}>0(<0)$, then the polluting good and clean environment are substitutes (complements) in consumption. For example, pollution and hiking activity can be considered as substitutes in consumption, while pollution and airconditioning devices can be considered as complements. On the other hand, assuming $E_{p r}=0$ implies that the polluting good and pollution (clean environment) are independent in consumption.

${ }^{7}$ Since the consumer prices of the non polluting goods and the producer prices of all goods are constant, they are omitted from the subsequent analysis.
} 
follow, since the countries are assumed to be small open economies and there are no distortions on the production side of either country.

Pollution generated in each country is transboundary and it affects negatively the utility of residents in both countries. Thus, total pollution affecting consumers in Home $(r)$ and Foreign $\left(r^{*}\right)$ are respectively denoted as:

$$
r=\alpha E_{p}+\theta \alpha^{*} E_{p^{*}}^{*} \text { and } r^{*}=\alpha^{*} E_{p^{*}}^{*}+\theta^{*} \alpha E_{p},
$$

where $0 \leq \theta \leq 1$ is the rate of the pollution generated in Foreign that affects consumers in Home, and similarly, $0 \leq \theta^{*} \leq 1$ is the rate of pollution generated in Home that affects consumers in Foreign.

The income-expenditure identity for Home requires that expenditure equals income from production plus the consumption tax revenue which is assumed to be lump sum distributed. That is

$$
E(u, p, r)=R(.)+\tau E_{p}(u, p, r) .
$$

Similarly, Foreign's income-expenditure identity is defined as

$$
E^{*}\left(u^{*}, p^{*}, r^{*}\right)=R^{*}(.)+\tau^{*} E_{p^{*}}^{*}\left(u^{*}, p^{*}, r^{*}\right)
$$

For analytical convenience, the following assumption is used hereon.

Assumption 1: All income effects fall on the non polluting goods, i.e., $E_{p u}=E_{p^{*} u^{*}}^{*}=E_{r u}=E_{r^{*} u^{*}}^{*}=0$.

Differentiating equations (2) and (3) we get that

$$
\begin{gathered}
E_{u} d u=\tau E_{p p} d \tau+\left[-E_{r}+\tau E_{p r}\right) d r \text { and } \\
E_{u^{*}}^{*} d u^{*}=\tau^{*} E_{p^{*} p^{*}}^{*} d \tau^{*}+\left[-E_{r^{*}}^{*}+\tau^{*} E_{p^{*} r^{*}}^{*}\right) d r^{*} .
\end{gathered}
$$

Differentiating equations (1), we obtain the effects in the levels of pollution $r$ and $r^{*}$ due to changes in the tax rates, in the rates of cross-border pollution, and in the rates of pollution per unit of consumption in the two countries as follows: 


$$
\begin{gathered}
{\left[\begin{array}{cc}
\delta & -\theta \alpha^{*} E_{p^{*} r^{*}}^{*} \\
-\theta^{*} \alpha E_{p r} & \delta^{*}
\end{array}\right]\left[\begin{array}{c}
d r \\
d r^{*}
\end{array}\right]=\left[\begin{array}{c}
\alpha E_{p p} \\
\theta^{*} \alpha E_{p p}
\end{array}\right] d \tau+\left[\begin{array}{c}
\theta \alpha^{*} E_{p^{*} p^{*}}^{*} \\
\alpha^{*} E_{p^{*} p^{*}}^{*}
\end{array}\right] d \tau^{*}} \\
+\left[\begin{array}{c}
\alpha^{*} E_{p^{*}}^{*} \\
0
\end{array}\right] d \theta+\left[\begin{array}{c}
0 \\
\alpha E_{p}
\end{array}\right] d \theta^{*}+\left[\begin{array}{c}
\theta E_{p^{*}}^{*} \\
E_{p^{*}}^{*}
\end{array}\right] d \alpha^{*}+\left[\begin{array}{c}
E_{p} \\
\theta^{*} E_{p}
\end{array}\right] d \alpha,
\end{gathered}
$$

where $\delta=1-\alpha E_{p r}$ and $\delta^{*}=1-\alpha^{*} E_{p^{*} r^{*}}^{*}$ are both positive under the plausible assumption that an increase in the consumption tax of the polluting good that reduces its consumption, given everything else, reduces the consumption generated pollution. Using the system of equations (6) we get that

$$
\begin{gathered}
\Delta d r=\alpha E_{p p} H d \tau+E_{p} H d \alpha+\delta^{*} \alpha^{*} E_{p^{*}}^{*} d \theta \\
+\theta \alpha^{*} E_{p^{*} p^{*}}^{*} d \tau^{*}+\theta E_{p^{*}}^{*} d \alpha^{*}+\alpha E_{p} \theta \alpha^{*} E_{p^{*} r^{*}}^{*} d \theta^{*} \text { and } \\
\Delta d r^{*}=\theta^{*} \alpha E_{p p} H d \tau+\theta^{*} E_{p} d \alpha+\alpha^{*} E_{p^{*}}^{*} \theta^{*} \alpha E_{p r} d \theta \\
+\alpha^{*} E_{p^{*} p^{*}}^{*} H^{*} d \tau^{*}+E_{p^{*}}^{*} H^{*} d \alpha^{*}+\delta \alpha E_{p} d \theta^{*}
\end{gathered}
$$

where $H=\left[1-\left(1-\theta \theta^{*}\right) \alpha^{*} E_{p^{*} r^{*}}\right]$ and $H^{*}=\left[1-\left(1-\theta \theta^{*}\right) \alpha E_{p r}\right]$ are both positive. ${ }^{8}$ The determinant of the left hand side of equations (6), denoted as $\Delta=1-\alpha^{*} E_{p^{*} r^{*}}^{*}-\alpha E_{p r}+\left(1-\theta \theta^{*}\right) \alpha E_{p r} \alpha^{*} E_{p^{*} r^{*}}^{*}$, is also positive under the assumption that an increase in Home's consumption tax on good 1 that reduces its consumption, it also reduces total pollution. Substituting equation (7) into equation (4), and (8) into (5), after some manipulations we get

$\Delta d u=A_{\tau} d \tau+A_{\tau^{*}} d \tau^{*}=E_{p p}\left[\tau \delta^{*}-\alpha E_{r} H\right] d \tau-\left[E_{r}-\tau E_{p r}\right] \theta \alpha^{*} E_{p^{*} p^{*}}^{*} d \tau^{*}$ and

\footnotetext{
${ }^{8}$ Note that $H=\delta$ when $\theta=\theta^{*}=0$ and $H=1$ when $\theta=\theta^{*}=1$. If $E_{p r}>0$, then $H>\delta$. If $E_{p r}<0$, then $H>0$. Similarly for $H^{*}$.
} 
$\Delta d u^{*}=B_{\tau^{*}} d \tau^{*}+B_{\tau} d \tau=E_{p^{*} p^{*}}^{*}\left[\tau^{*} \delta-\alpha^{*} E_{r^{*}}^{*} H^{*}\right] d \tau^{*}-\left[E_{r^{*}}^{*}-\tau^{*} E_{p^{*} r^{*}}^{*}\right] \theta^{*} \alpha E_{p p} d \tau$.

Equation (9) shows that an increase in Home's consumption tax rate $\tau$ affects utility through a negative tax revenue effect, i.e., $\Delta^{-1} E_{p p} \tau \delta^{*}$, due to lower consumption and consumption tax revenue. The term $-\Delta^{-1} E_{p p} \alpha E_{r} H$, captures the effect of the higher $\tau$ on Home's utility through the induced changes in the level of pollution. That is, the higher $\tau$ which lowers $r$, exerts through this term a positive impact on welfare. The second right-hand-side term of this equation captures the impact of a higher $\tau^{*}$ on Home's utility. A higher $\tau^{*}$ which reduces Home pollution due to lower cross-border pollution, on the one hand, has a positive direct impact on $u$, i.e., $-\Delta^{-1} E_{r} \theta \alpha^{*} E_{p^{*} p^{*}}^{*}$, and on the other hand, an ambiguous indirect effect, i.e., $\Delta^{-1} \tau E_{p r} \theta \alpha^{*} E_{p^{*} p^{*}}^{*}$, through the change in consumption tax revenue, depending on the sign of $E_{p r}$. That is, a higher $\tau^{*}$, ceteris paribus, lowers cross-border pollution to Home. If the polluting good and pollution are complements in consumption, i.e., $E_{p r}>0$, then consumption of the polluting good falls and so do consumption tax revenues, entailing a negative impact on Home's utility. If the polluting good and pollution are substitutes in consumption, i.e., $E_{p r}<0$, the opposite result holds. Similar interpretations can be given for the terms in equation (10).

\section{Nash Equilibrium}

First, we consider the case where each country chooses its consumption tax to maximize its own welfare taking as given the policy of the other country. The reaction functions of the two countries are given by

$$
\begin{aligned}
& \Delta \frac{\partial u}{\partial \tau}=A_{\tau}=E_{p p}\left\{\tau\left[1-\alpha^{*} E_{p^{*} r^{*}}^{*}\right]-\alpha E_{r}\left[1-\left(1-\theta \theta^{*}\right) \alpha^{*} E_{p^{*} r^{*}}^{*}\right]\right\}=0 \text { and } \\
& \Delta \frac{\partial u^{*}}{\partial \tau^{*}}=B_{\tau^{*}}=E_{p^{*} p^{*}}^{*}\left\{\tau^{*}\left[1-\alpha E_{p r}\right]-\alpha^{*} E_{r^{*}}^{*}\left[1-\left(1-\theta \theta^{*}\right) \alpha E_{p r}\right]\right\}=0
\end{aligned}
$$


Using equation (11), we obtain Home's Nash consumption tax rate as

$$
\tau^{N}=\frac{\alpha E_{r}\left[1-\left(1-\theta \theta^{*}\right) \alpha^{*} E_{p^{*} r^{*}}^{*}\right]}{\left[1-\alpha^{*} E_{p^{*} r^{*}}^{*}\right]} .
$$

Equation (13) shows that the Nash equilibrium consumption tax is positive. In the case where any of $\theta, \theta^{*}$ and or $E_{p^{*} r^{*}}^{*}$ are zero, then the Nash consumption tax reduces to $\tau^{N}=\alpha E_{r}$, which corresponds to the Nash equilibrium tax rate when pollution is only local. ${ }^{9}$ When there is perfect or imperfect crossborder pollution between the two countries, (i.e., $0<\theta^{*} \leq 1 ; 0<\theta \leq 1$ ) then, ceteris paribus, Home's Nash equilibrium consumption tax with cross border pollution is higher (lower) to the Nash rate in the absence of cross border pollution if $E_{p^{*} r^{*}}^{*}$ is positive (negative). Intuitively, a consumption tax on this good, by reducing its consumption, affects negatively welfare by reducing tax revenue and positively by reducing pollution. An increase in the consumption tax in Home, reduces local consumption and pollution, thus less pollution is trasmitted in Foreign. If $E_{p^{*} r^{*}}^{*}>0$, then in Foreign lower pollution reduces the consumption of the polluting good since this good and pollution are complements in consumption. This in turn results in less cross-border pollution from Foreign to Home, thus affecting positively Home's welfare. This positive effects calls for higher Nash equilibrium consumption tax in Home. Similarly, setting $B_{\tau^{*}}=0$ in equation (12), we obtain Foreign's Nash equilibrium consumption tax.

The second order conditions for welfare maximization are satisfied if

$$
\begin{gathered}
\Delta \frac{\partial^{2} u}{\partial \tau^{2}}=A_{\tau \tau}=E_{p p}\left[\delta^{*}-\alpha^{2} H^{2} E_{p p} E_{r r} \Delta^{-1}-\alpha H E_{r p}\right] \text { and } \\
\Delta \frac{\partial^{2} u^{*}}{\partial \tau^{* 2}}=B_{\tau^{*} \tau^{*}}=E_{p^{*} p^{*}}^{*}\left[\delta-\alpha^{* 2} H^{* 2} E_{p^{*} p^{*}}^{*} E_{r^{*} r^{*}}^{*} \Delta^{-1}-\alpha^{*} H^{*} E_{r^{*} p^{*}}^{*}\right]
\end{gathered}
$$

are negative. Sufficient but not necessary conditions for these to be satisfied is that pollution and the polluting good are substitutes in consumption in

\footnotetext{
${ }^{9}$ When pollution is generated from production, the existence of cross-border pollution does not affect the expression of the Nash equilibrium emision tax, see e.g., Hatzipanayotou et al (2005).
} 
each country, i.e., $E_{r p} \leq 0$ in Home and $E_{r^{*} p^{*}}^{*} \leq 0$ in Foreign. In the case where $E_{r p}$ and $E_{r^{*} p^{*}}^{*}$ are positive, it is assumed that are sufficiently small so that the second order conditions for welfare maximization are satisfied. Differentiating the reactions functions of Home (i.e., equation (11)) and of Foreign (i.e., equation (12)), with respect to $\tau^{*}$ and $\tau$ respectively, we get

$$
\begin{aligned}
& \Delta \frac{\partial A_{\tau}}{\partial \tau^{*}}=A_{\tau \tau^{*}}=-\alpha \alpha^{*} \theta H E_{r r} E_{p p} E_{p^{*} p^{*}}^{*} \Delta^{-1}<0 \text { and } \\
& \Delta \frac{\partial B_{\tau^{*}}}{\partial \tau}=B_{\tau^{*} \tau}=-\alpha \alpha^{*} \theta^{*} H^{*} E_{r^{*} r^{*}}^{*} E_{p p} E_{p^{*} p^{*}}^{*} \Delta^{-1}<0 .
\end{aligned}
$$

The slope of Home's reaction function (i.e., $\left.\left.\left(d \tau^{*} / d \tau\right)\right|_{A_{\tau}=0}=-A_{\tau \tau} / A_{\tau \tau^{*}}\right)$

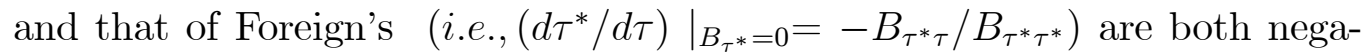
tive, indicating that the Nash consumption taxes are strategic substitutes. Stability of the Nash equilibrium requires that Home's reaction function is steeper.

Proposition 1 Consider two countries and assume the existence of consumption generated cross-border pollution between them.

- If in Foreign pollution and the polluting good are substitutes (complements) in consumption, then the Home Nash equilibrium consumption tax rate is lower (higher) compared to the case where cross-border pollution is absent.

- If in Foreign the pollution and the polluting good are independent is consumption, then the existence of cross-border pollution does not affect the Nash equilibrium consumption tax in Home.

\subsection{Comparative Statics}

In this subsection we consider the effects on the Nash equilibrium consumption tax rates of changes in the rates of pollution per unit of consumption in 
the two countries, and in the rates of cross-border pollution. Totally differentiating equations (11) and (12), we get

$$
\begin{gathered}
{\left[\begin{array}{cc}
A_{\tau \tau} & A_{\tau^{*}} \\
B_{\tau^{*} \tau} & B_{\tau^{*} \tau^{*}}
\end{array}\right]\left[\begin{array}{c}
d \tau^{N} \\
d \tau^{N *}
\end{array}\right]=-\left[\begin{array}{c}
A_{\tau \alpha} \\
B_{\tau^{*} \alpha}
\end{array}\right] d \alpha-\left[\begin{array}{c}
A_{\tau \alpha^{*}} \\
B_{\tau^{*} \alpha^{*}}
\end{array}\right] d \alpha^{*}} \\
-\left[\begin{array}{c}
A_{\tau \theta} \\
B_{\tau^{*} \theta}
\end{array}\right] d \theta-\left[\begin{array}{c}
A_{\tau \theta^{*}} \\
B_{\tau^{*} \theta^{*}}
\end{array}\right] d \theta^{*}
\end{gathered}
$$

\subsubsection{The effect of changes in rates of pollution per unit of con- sumption}

Using the system of equations (18) we get the effect on the Nash equilibrium consumption taxes in both countries of changes in Home's rate of pollution per unit of consumption as:

$$
\begin{gathered}
\Omega \frac{d \tau^{N}}{d \alpha}=-B_{\tau^{*} \tau^{*}} A_{\tau \alpha}+A_{\tau \tau^{*}} B_{\tau^{*} \alpha} \text { and } \\
\Omega \frac{d \tau^{* N}}{d \alpha}=-B_{\tau^{*} \alpha} A_{\tau \tau}+B_{\tau^{*} \tau} A_{\tau \alpha}
\end{gathered}
$$

where $\Omega=A_{\tau \tau} B_{\tau^{*} \tau^{*}}-B_{\tau^{*} \tau} A_{\tau \tau^{*}}$ is the determinant of the left hand side of equations (18) and is positive for the stability of the Nash equilibrium. Also $B_{\tau^{*} \alpha}=-\alpha^{*} \theta^{*} E_{p^{*} p^{*}}^{*}\left[\theta \delta^{-1} E_{p r} E_{r^{*}}^{*}+H^{*} E_{p} E_{r^{*} r^{*}}^{*} \Delta^{-1}\right]$ and $A_{\tau \alpha}=-H E_{p p}\left[E_{r}+\right.$ $\left.\alpha H E_{r r} E_{p} \Delta^{-1}\right]>0$. In general, the effect of an increase in $\alpha$ on the Nash equilibrium consumption taxes is ambiguous. For improving the understanding of these results, we consider some special cases. First, let pollution and the polluting good be very strong substitutes, i.e., $E_{p r}$ is a large negative number in absolute terms, and let $\theta$ be close to one, so that $B_{\tau^{*} \alpha}<0,{ }^{10}$ then an increase in $\alpha$ increases the Nash consumption tax in Home and decreases it in Foreign. This case can be explained using Figures 1 and 2. As noted in equations (16) and (17), the reaction functions of both countries have nega-

\footnotetext{
${ }^{10} \theta \simeq 1$ implies near (or) perfect cross-border pollution. This is a commonly used assumption in the relevant literature, e.g., see Vlassis (2012).
} 
tive slopes. Point $A$ on both diagrams depicts the initial Nash equilibrium. Since $A_{\tau \alpha}$ is positive, an increase in $\alpha$ moves the Home reaction function $R R$ upwards (i.e., $\left.\left.\left(d \tau^{*} / d \alpha\right)\right|_{A_{\tau}=0}=-A_{\tau \alpha} / A_{\tau^{*}}>0\right)$. Since the sign of $B_{\tau^{*} \alpha}$ is ambiguous, the Foreign reaction function $R^{*} R^{*}$ moves upwards or downwards depending on the sign of $E_{p r}$. If $E_{p r}$ is negative and $\left|E_{r} \delta^{-1} E_{p r}\right|>E_{r r} E_{p} \Delta^{-1}$, then $B_{\tau^{*} \alpha}$ is negative and the Foreign reaction function moves downwards resulting in a lower Nash consumption tax in Foreign and a higher one in Home. This is shown in Figure 1 where the initial Nash equilibrium is at A and the new Nash equilibrium is at point $B$. If, however, $E_{p r}$ is positive, then $B_{\tau^{*} \alpha}$ is positive and the Foreign reaction function moves upwards and the new Nash equilibrium could be at a point such as C, D or E shown in Figure 2. If the new Nash equilibrium is at $\mathrm{C}$, then, the result is a lower Foreign and a higher Home Nash consumption tax. If instead the new Nash equilibrium is at $\mathrm{D}$, then the result is a higher Nash consumption tax in both countries. It is even possible that the new Nash equilibrium is at a point like E with a lower Home and a higher Foreign Nash consumption tax. Intuitively, when $\alpha$ increases, Home's reaction is to increase its Nash consumption tax. The best response by Foreign, on the one hand, is to reduce its Nash tax rate. On the other hand, when $\alpha$ increases, more pollution gets into Foreign. In Foreign when pollution increases i) $E_{r^{*}}^{*}$ increases, since $E_{r^{*} r^{*}}^{*}$ is positive, calling for a higher tax and ii) If $E_{p r}$ is positive, then Home's consumption of the polluting good increases, which in turn for given rate $\theta$, raises pollution in Foreign calling for a higher Nash consumption tax in that country. If, however, $E_{p r}$ is negative, Home's consumption of the polluting good falls, and pollution in Foreign declines, calling for a lower Nash consumption tax in the country. The final result depends on the relative size of each of these effects. ${ }^{11}$

\footnotetext{
${ }^{11}$ Consider the special case where either $\theta$ or $\theta^{*}$ is zero, which implies that either $A_{\tau \tau^{*}}$ or $B_{\tau^{*} \alpha}$ is zero. Then, an increase in $\alpha$, increases Home's Nash consumption tax rate. The same holds when initially $\alpha$ is very small and thus $B_{\tau^{*} \tau}$ is close to zero. Similarly, when $\alpha$ increases, then the optimal response by Foreign is to increase its Nash consumption tax rate when initially $\alpha$ is very small and $E_{p r}$ is either non-negative or a sufficiently small negative number so that $B_{\tau^{*} \alpha}$ is positive.
} 


\subsubsection{The effect of changes in the rate of cross border pollution}

Using the system of equations (18) we get the effect on the Nash equilibrium consumption taxes in both countries of changes in the rate of cross border pollution as:

$$
\begin{gathered}
\Omega \frac{d \tau^{N}}{d \theta}=-A_{\tau \theta} B_{\tau^{*} \tau^{*}}+A_{\tau \tau^{*}} B_{\tau^{*} \theta} \text { and } \\
\Omega \frac{d \tau^{* N}}{d \theta}=-A_{\tau \tau} B_{\tau^{*} \theta}+A_{\tau \theta} B_{\tau^{*} \tau}
\end{gathered}
$$

where $B_{\tau^{*} \theta}=-\alpha \alpha^{*} \theta^{*} E_{p r} E_{p^{*} p^{*}}^{*}\left[E_{r^{*}}^{*}+\alpha^{*} H^{*} E_{p^{*}}^{*} E_{r^{*} r^{*}}^{*} \Delta^{-1}\right], A_{\tau \theta}=-\alpha \alpha^{*} E_{p p}$ $\left[\theta^{*} E_{r} E_{p^{*} r^{*}}^{*}+H \delta^{*} E_{r r} E_{p^{*}}^{*} \Delta^{-1}\right]$. In general, the effects of changes in $\theta$ on the Nash equilibrium tax rates is ambiguous. Like in the previous discussion, we consider some special cases for better understanding these effects. First, consider the case where $E_{p r}<0$ and thus $B_{\tau^{*} \theta}<0$, and $E_{p^{*} r^{*}}^{*}$ is either positive or has a sufficiently small negative value so that $A_{\tau \theta}>0$. In this case, an increase in $\theta$ increases Home's Nash equilibrium consumption tax rate and it reduces that of Foreign. This case can be explain using Figure 1. Since $A_{\tau \theta}>0$, the increase in $\theta$ shifts upwards Home's reaction function, and since $B_{\tau^{*} \theta}<0$, Foreign's reaction function moves downwards. The new Nash equilibrium is at point $B$ with a higher Home consumption tax and a lower tax in Foreign. If, however, $E_{p r}$ and $E_{p^{*} r^{*}}^{*}$ are both positive, then both reaction functions shift upwards resulting in a new Nash equilibrium such as $\mathrm{C}$ with a lower Foreign and a higher Home consumption tax, or such as D with higher consumption taxes in both countries, or even to a point like $\mathrm{E}$ with a higher consumption tax in Foreign and a lower one in Home, see fig $2 .^{12}$

Proposition 2 Consider two countries and assume the existence of consumption generated cross-border pollution between them.

- An increase in the pollution per unit of consumption in Home, increases

\footnotetext{
${ }^{12}$ In the special case where $\theta^{*}=0$, then $B_{\tau^{*} \theta}=0$, and an increase in $\theta$ increases Home's Nash consumption tax rate. If initially $\theta$ is close to zero, then $A_{\tau \tau^{*}} \approx 0$ and an increase in this rate increases Home's Nash tax rate if $E_{p^{*} r^{*}}^{*} \geq 0$.
} 
that country's Nash equilibrium consumption tax and decreases it in Foreign if in Home pollution and the polluting good are strong substitutes and $\theta$ is close to one so that $B_{\tau^{*} \alpha}<0$.

- An increase in the rate of cross-border pollution into Home, increases the Nash equilibrium consumption tax in Home and decreases it in Foreign if i) in Home pollution and the polluting good are substitutes i.e, $E_{p r}<0$, and ii) $E_{p^{*} r^{*}}^{*}$ is either positive or has sufficiently small negative value so that $A_{\tau \theta}>0$.

\section{Cooperative Equilibrium}

In this section we consider the case where each country chooses its consumption tax rate in order to maximize the joint welfare of both countries. That is

$$
\frac{\partial u}{\partial \tau}+\frac{\partial u^{*}}{\partial \tau}=A_{\tau}+B_{\tau}=0 \quad \text { and } \quad \frac{\partial u^{*}}{\partial \tau^{*}}+\frac{\partial u}{\partial \tau^{*}}=B_{\tau^{*}}+A_{\tau^{*}}=0 .
$$

Using equation (9) and (10) we get that

$$
\left[\begin{array}{cc}
\delta^{*} & \alpha \theta^{*} E_{p^{*} r^{*}}^{*} \\
\alpha^{*} \theta E_{p r} & \delta
\end{array}\right]\left[\begin{array}{c}
\tau^{c} \\
\tau^{c *}
\end{array}\right]=\left[\begin{array}{c}
\alpha\left(H E_{r}+\theta^{*} E_{r^{*}}^{*}\right) \\
\alpha^{*}\left(H^{*} E_{r^{*}}^{*}+\theta E_{r}\right)
\end{array}\right] .
$$

From equations (24) we get the cooperative consumption tax for each country as follows:

$$
\begin{array}{r}
(\Delta / \delta) \tau^{c}=\alpha\left[\left(H E_{r}+\theta^{*} E_{r^{*}}^{*}\right)-\alpha^{*} \theta^{*} E_{p^{*} r^{*}}^{*}\left(H^{*} E_{r^{*}}^{*}+\theta E_{r}\right) \delta^{-1}\right] \text { and } \\
\left(\Delta / \delta^{*}\right) \tau^{* c}=\alpha^{*}\left[\left(H^{*} E_{r^{*}}^{*}+\theta E_{r}\right)-\alpha \theta E_{p r}\left(H E_{r}+\theta^{*} E_{r^{*}}^{*}\right) \delta^{*-1}\right] .
\end{array}
$$




\subsection{Comparison of the Nash and Cooperative Equilib- rium Taxes}

It is well established that, in the presence of a production generated pollution and cross-border pollution, the cooperative equilibrium taxes are higher than Nash equilibrium taxes, since they internalize its damaging impact to all parties involved. ${ }^{13}$ Now, in the context of our model, we are set to identify the cases where the cooperative equilibrium consumption taxes are indeed higher than the Nash equilibrium taxes, but we also look for cases where the opposite result may hold.

From equation (13) Home's Nash consumption tax rate can be re-written as

$$
\delta^{*} \tau^{N}=\alpha H E_{r}
$$

Note that $(\Delta / \delta)=\delta^{*}-\left(\alpha \alpha^{*} \theta \theta^{*} E_{p r} E_{p^{*} r^{*}}^{*}\right) \delta^{-1}$. Thus if $E_{p r}$ and $E_{p^{*} r^{*}}^{*}$ have the same sign, then $(\Delta / \delta)<\delta^{*}$. Comparing equations (25) and (27), we observe that if $E_{p^{*} r^{*}}^{*} \leq 0$, then always the cooperative consumption tax is greater than the Nash consumption tax rate. Intuitively, when Home increases the consumption tax on the polluting good, its consumption and pollution is reduced and thus the level of pollution transmitted into Foreign falls. Since in Foreign pollution and the consumption of the polluting good are substitutes, the country's consumption of this good increases, thus raising its pollution. Given that Home cares also about the welfare of Foreign, it raises its consumption tax more in order for even less pollution to be trasmitted into Foreign. In the case where no pollution is transmitted into Foreign (i.e., $\theta^{*}=0$ ), then always and irrespectively of the size of $\theta, \tau^{c}=$ $\tau^{N}$. When $\theta=0$ and $\theta^{*} \neq 0$, then $(\Delta / \delta)=\delta^{*}, \delta^{*}=H$, and $\delta=H^{*}$. In this case $\tau^{c}=\alpha E_{r}+\alpha \theta^{*} E_{r^{*}}^{*}$. That is, the cooperative consumption tax is always greater than the Nash consumption tax.

In the case where pollution and the consumption of the polluting good are

\footnotetext{
${ }^{13}$ See, for example, Lapan and Sikdar (2011) where they showed that efficiency requires that both countries internalize the domestic and transboudary effects of emisions.
} 
complements in consumption in Foreign (i.e., $E_{p^{*} r^{*}}^{*}>0$ ), then it is possible that the cooperative consumption tax rate is smaller than the corresponding Nash tax rate. This is more likely to occur when $\theta, \alpha^{*}$ and $E_{p^{*} r^{*}}^{*}$ are large. Intuitively, in this case when Home increases the consumption tax on the polluting good, its consumption and pollution falls and less pollution is trasmitted into Foreign. Since pollution and the polluting good are complements in consumption, consumption of the polluting good and pollution in Foreign are reduced a lot given that $\alpha^{*}$ and $E_{p^{*} r^{*}}^{*}$ are assumed large. Thus, a lot less pollution is trasmitted to Home. In this case it is possible that the cooperative consumption tax is lower than the Nash tax.

Consider, for example, the special case where there is perfect transboundary pollution (i.e., $\theta=\theta^{*}=1$ ). In this case $H=H^{*}=1$ and $\Delta=1-\alpha^{*} E_{p^{*} r^{*}}^{*}-\alpha E_{p r}$ and it can be shown that $\tau^{c}=\alpha\left(E_{r^{*}}^{*}+E_{r}\right)$ and the difference between the cooperative and Nash equilibrium consumption taxes is

$$
\tau^{c}-\tau^{N}=\alpha\left(E_{r^{*}}^{*}-\delta^{*-1} E_{r} \alpha^{*} E_{p^{*} r^{*}}^{*}\right)=\delta^{*-1} \alpha\left[E_{r^{*}}^{*}-\alpha^{*} E_{p^{*} r^{*}}^{*}\left(E_{r}+E_{r^{*}}^{*}\right)\right] .
$$

It is clear from the above expression that when pollution and the polluting good are complements in consumption in Foreign (i.e., $E_{p^{*} r^{*}}^{*}>0$ ), that the cooperative tax in Home can be lower than its Nash tax. This outcome is more likely when $\alpha^{*}$ and $E_{p^{*} r^{*}}^{*}$ are large and $E_{r}$ is much larger than $E_{r^{*}}^{*}$.

Proposition 3 Consider two countries and assume the existence of consumption generated cross-border pollution between them.

- If in Foreign, pollution and the polluting good are substitutes or independent in consumption, then Home's cooperative consumption tax is always greater than its corresponding Nash tax rate.

- If in Foreign, pollution and the polluting good are complements in consumption, then Home's cooperative consumption tax can be lower than 
its corresponding Nash rate.

\subsection{Comparison of the Coopetative Consumption Taxes of the Two Countries}

Now we examine cases where although both countries choose their consumption taxes cooperatively, this cooperation, however, may entail the choice of different optimal consumption taxes. We consider two cases, i) when the two countries differ in the rate of cross border pollution and ii) when they differ in the rate of pollution per unit of consumption.

\subsubsection{Differences in the rate of cross border pollution}

First, consider the case where the two countries are identical in some respects. That is $E_{r^{*}}^{*}=E_{r}$, and $\alpha^{*}=\alpha$, but $\theta=0$ and $\theta^{*} \neq 0$. In this case $\delta^{*}=H, \delta=$ $H^{*},(\Delta / \delta)=\delta^{*}$ and $\left(\Delta / \delta^{*}\right)=\delta$. Under these assumptions, equations (25) and (26) give that $\tau^{* c}=\alpha^{*} E_{r^{*}}^{*}$ and $\tau^{c}=\alpha E_{r}+\alpha \theta^{*} E_{r^{*}}^{*}=\alpha E_{r}\left(1+\theta^{*}\right)$. Thus, even though the two countries are the same in some respects, and choose their policy to maximize their joint welfare, the country that trasmits pollution into the other country will choose higher cooperative consumption tax. For example, if $\theta^{*}=0.5$, then Home cooperative consumption tax will be $50 \%$ higher that the corresponding one of the Foreign. ${ }^{14}$ The intuition is simple. Since consumption at Home pollutes Foreign, when Home decides on its optimal consumption tax, its has to take into account the damage that it causes to Foreign.

\subsubsection{Differences in the rate of pollution per unit of consumption}

Next, consider the case where the two countries differ in the pollution per unit of consumption. Assume for example that $\theta=\theta^{*}=1$. In this case $H^{*}=$

\footnotetext{
${ }^{14}$ This can be the case where we have only downstream transmission of pollution. That is, the pollution is generated in one country and is trasmitted into the other either with water (i.e., rivers) or with air if the wind is usually coming from one direction.
} 
$H=1$. The optimal cooperative policy for Home calls for a consumption tax $\tau^{c}=\alpha\left(E_{r^{*}}^{*}+E_{r}\right)$, while for Foreign it calls for a tax $\tau^{* c}=\alpha^{*}\left(E_{r^{*}}^{*}+E_{r}\right)$. Thus, given everything else, we can say that the country with a low rate of pollution per unit of consumption imposes a small cooperative consumption tax while the country with a high rate of pollution per unit of consumption imposes a high cooperative consumption tax. ${ }^{15}$

Proposition 4 Consider two countries which cooperate in their choice of consumption taxes, and assume the existence of consumption generated crossborder pollution between them

- If the two countries differ only in the rate of cross border pollution, then the country that transmits pollution into the other chooses a higher cooperative consumption tax rate.

- If the two countries differ only in the rate of pollution per unit of consumption, then the country with the higher rate of pollution per unit of consumption chooses a higher cooperative consumption tax.

A common result of the tax competition literature is that the first best allocation is achieved by harmonizing the tax policies in the two countries. In the present model, however, with cross border pollution, this may not be achieved by coordinating only consumption taxes. Coordination in other policies may also be needed in order to achieve the first best. For example, if the pollutions per unit of consumption in the two countries are different, then measures have to be takes in both countries in order to equalize these and then bring consumption taxes towards uniformity. ${ }^{16}$

\footnotetext{
${ }^{15}$ Let petrol be the polluting good. One country can have relatively low pollution per unit of consumption if its residents, responding to strict legislation or incentives, use cars with efficient engines (relatively new and well maintened cars) and efficient burners (new and well maintened) to heat their homes.

${ }^{16}$ Cremer and Gahvari (2005) using a two country model with transboundary pollution generated from production, concluded that harmonizing the commodity taxes above their Nash rates while leaving the Nash emmision taxes unaffected, may increase pollution and reduce welfare.
} 


\section{Concluding Remarks}

This paper builds a many-good, two-small open economies model. The consumption of good 1 in each country generates pollution which is transmitted across borders and affects negatively consumers in both countries. Within this model, we find among other things, that Home Nash equilibrium consumption tax rate is affected by the rates of cross-border pollution into both, by the rate of pollution per unit of consumption in both countries and depends also on the relationship in consumption between pollution and the polluting good in Foreign (i.e., complements or substitutes). The effect of an increase in Home's rate of pollution per unit of consumption, or its rate of cross-border pollution, has in general an ambiguous effect on both countries Nash consumption tax rates. These effects depend, among other things, on the initial rates of pollution per unit of consumption, on the rates of cross border pollution and on the relationship in consumption between pollution and the polluting good in both countries. The paper identify cases where unambiguous results can be obtained.

The paper derives the cooperative equilibrium consumption taxes and compares them with those of the Nash equilibrium. For example, if pollution and the polluting good are substitutes or independent in consumption in one country, then the cooperative consumption tax of the other country is greater than its Nash tax rate. If, however, pollution and the polluting good in one country are complements in consumption, then the cooperative consumption tax of the other country can be lower compared to its Nash consumption tax rate.

Finally, even if two countries may only differ in the rates of pollution per unit of consumption, or in the rates of cross-border pollution, then their cooperative consumption taxes can be different. This last result may carry important policy implications, particularly within the context of tax harmonization and economic integration. For example, within the common market in the EU, consumption taxation is effectively "origin" based (pay taxes in the location of purchase). As a result, when producer prices are the same and there is cross-border shopping, consumers would purchase the products 
from the country where consumption taxes are lower. This in effect makes a necessity the consumption tax harmonization and equalization of consumer prices across countries when they move to deeper stages of economic integration. Yet, the present analysis concludes that in the presence of consumption generated cross-border pollution, when countries differ with respect to some of their characteristics, e.g., the rates of pollution per unit of consumption, then tax harmonization is not the optimal policy. In this case further actions are needed for the tax harmonization to be optimum. For example, before the countries decide on harmonizing their consumptions taxes they should try to harmonize their legislation and take other harmonizing measures in order for the pollution per unit of consumption in all the countries to be the same.

\section{References}

Abe, K., 1995, The target rates of tariffs and tax reforms, International Economic Review 36, 875-885.

Albrecht, J., 2006, The use of consumption taxes to re-launch green tax reforms, International Review of Law and Economics 26, 88-103.

Antweiler, A., B. Copeland and M. S. Taylor, 2001, Is free trade good for the environment?, American Economic Review 91, 877-908.

Atkinson, A.B. and Stiglitz, J.E., 1976. The design of tax structure: Direct versus indirect taxation, Journal of Public Economics, 6, 55- 75 .

Beghin, J., D. Holst and D. van der Mensbrugghe, 1997, Trade and pollution linkages: piecemeal reform and optimal intervention, Canadian Journal of Economics 30, 442-455.

Boadway, R. and M. Sato, 2009, Optimal tax design and enforcement with an informal sector, American Economic Journal: Economic Policy 1, $1-27$.

Bovenberg, L., 1994, Destination and origin based taxation under international capital mobility, International Tax and Public Finance 1, 247-273.

Browning, E.K., 1985, On the marginal welfare cost of taxation, American 
Economic Review 77, 11-23.

Copeland, B., 1994, International trade and the environment: policy reform in a polluted small open economy, Journal of Environmental Economics and Management 26, 44-65.

Cremer, H. and F. Gahvari, 2005, Environmental taxation in open economies: Unilateralism or partial harmonization, Southern Economic Journal 72, 352371.

Diamond, P., and J. Mirrlees, 1971, Optimal taxation and public production: Production efficiency, American Economic Review 61, 1-27.

Emran, S. and J. Stiglitz, 2005, On selective indirect tax reform in developing countries, Journal of Public Economics 89, 599-623.

Georgakopoulos, T. and T. Hitiris, 1992, On the superiority of the destination over the origin principle of taxation for intra-union trade, Economic Journal 102, 117-126.

Hatta, T., 1986, Welfare effects of changing commodity tax rates towards uniformity, Journal of Public Economics 29, 99-112.

Haibara, T., and H. Ohta, 2011, A new proposal for ecological tax reforms, GSICS Working Papers Series no. 24, Kobe University

Haibara, T., 2012, Alternative approaches to tax reform, Economics Letters $117,408-410$.

Hatzipanayotou, P., S. Lahiri and M. S. Michael (2005), "Reforms of Environmental Policies in the Presence of Cross-border Pollution and Publicprivate Clean-up", The Scandinavian Journal of Economics 107 (2) pp. 315333.

Karakosta, O., C. Kotsogiannis and M-A. Lopez-Garcia, Indirect tax harmonization and global public goods, International Tax and Public Finance, forthcoming.

Kayalica, O. and O. Kayalica, 2005, Transboundary pollution from consumption in a reciprocal dumping model, Global Economy Review 5, Article 7.

Keen, M. and S. Lahiri, 1998, The comparison between destination and origin principles under imperfect competition, Journal of International Economics, 45, 323-350. 
Keen, M. and J. Ligthart, 2002, Coordinating tariff reduction and domestic tax reform, Journal of International Economics 56, 489-507.

Lapan, H. E., and S. Sikdar, 2011, Strategic environmental policy under free trade with transboundary pollution, Review of Development Economics $15,1-18$.

Lahiri, S. and A. Nasimi, 2005, Commercial policy reform in Pakistan: Opening up the economy under revenue constraint, International Tax and Public Finance 12, 7234-739.

Michael, M., P. Hatzipanayotou and S. Miller, 1993, Integrated reforms of tariffs and consumption taxes, Journal of Public Economics 52, 417-428.

Michael, M. and P. Hatzipanayotou, 2013, Pollution and reforms of domestic and trade taxes towards uniformity, International Tax and Public Finance 20, 753-768.

OECD, 2012, Consumption tax trends: VAT/GST and excise rates, trends and administration issues. Chapter 6: Taxing vehicles, 137-142, Paris: OECD.

Stamatova, S., and A. Steurer, 2011, Environment and energy, EUROSTAT statistics focus, no 67.

Turunen-Red, A. and A. Woodland, 2004, Multilateral reforms on trade and environmental policy, Review of International Economics 12, 321-336.

Vlassis, N., 2012, The welfare consequences of pollution-tax harmonization, Environmental and Resource Economics, forthcoming. 


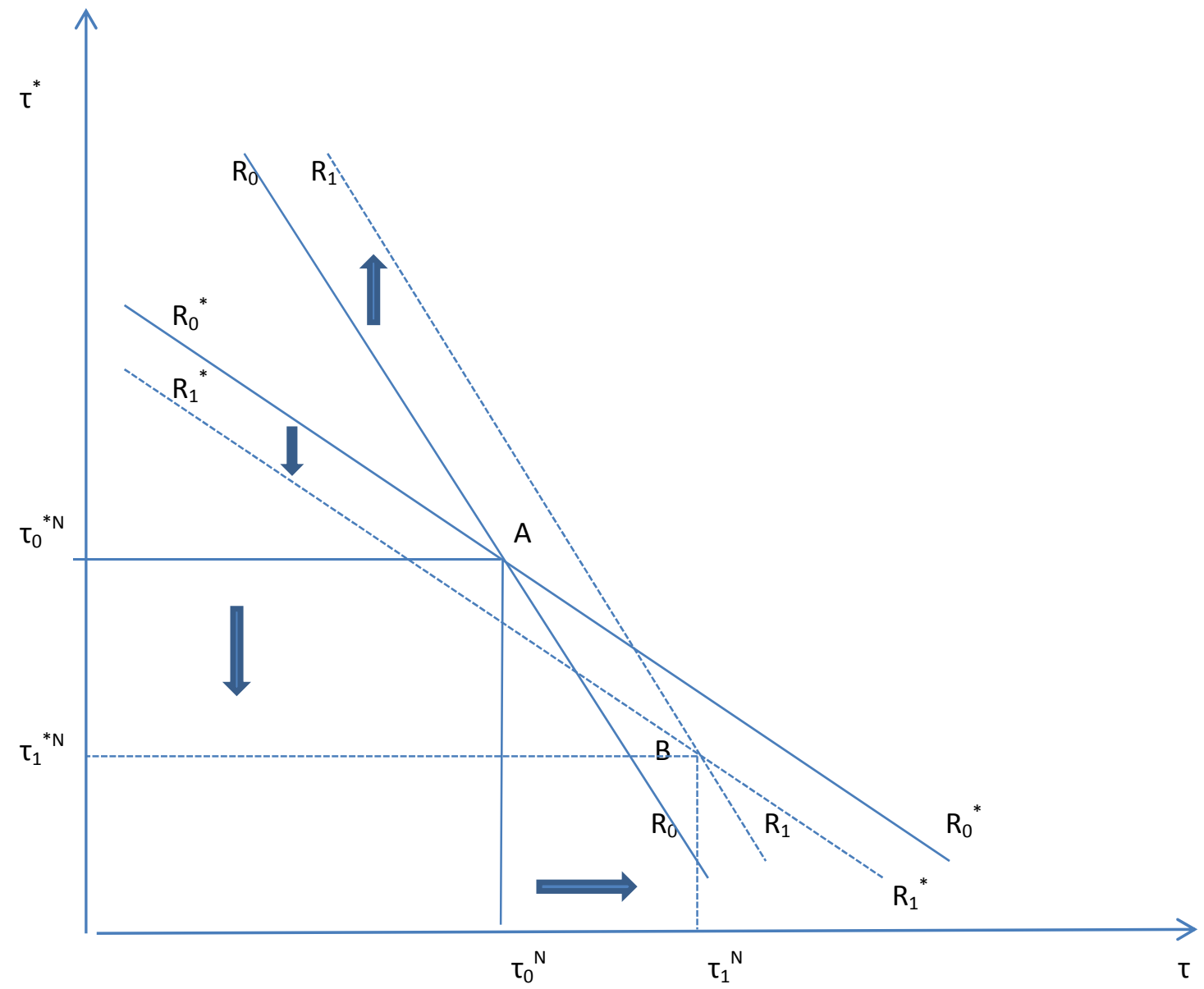

Fig. 1. Solid lines depict the initial Nash equilibrium. An increase in the pollution per unit of consumption at Home in this case moves to the right the Home reaction function RR and to the left the Foreign reaction function $\mathrm{R}^{*} \mathrm{R}^{*}$ resulting in a higher consumption tax at Home and lower in Foreign. 


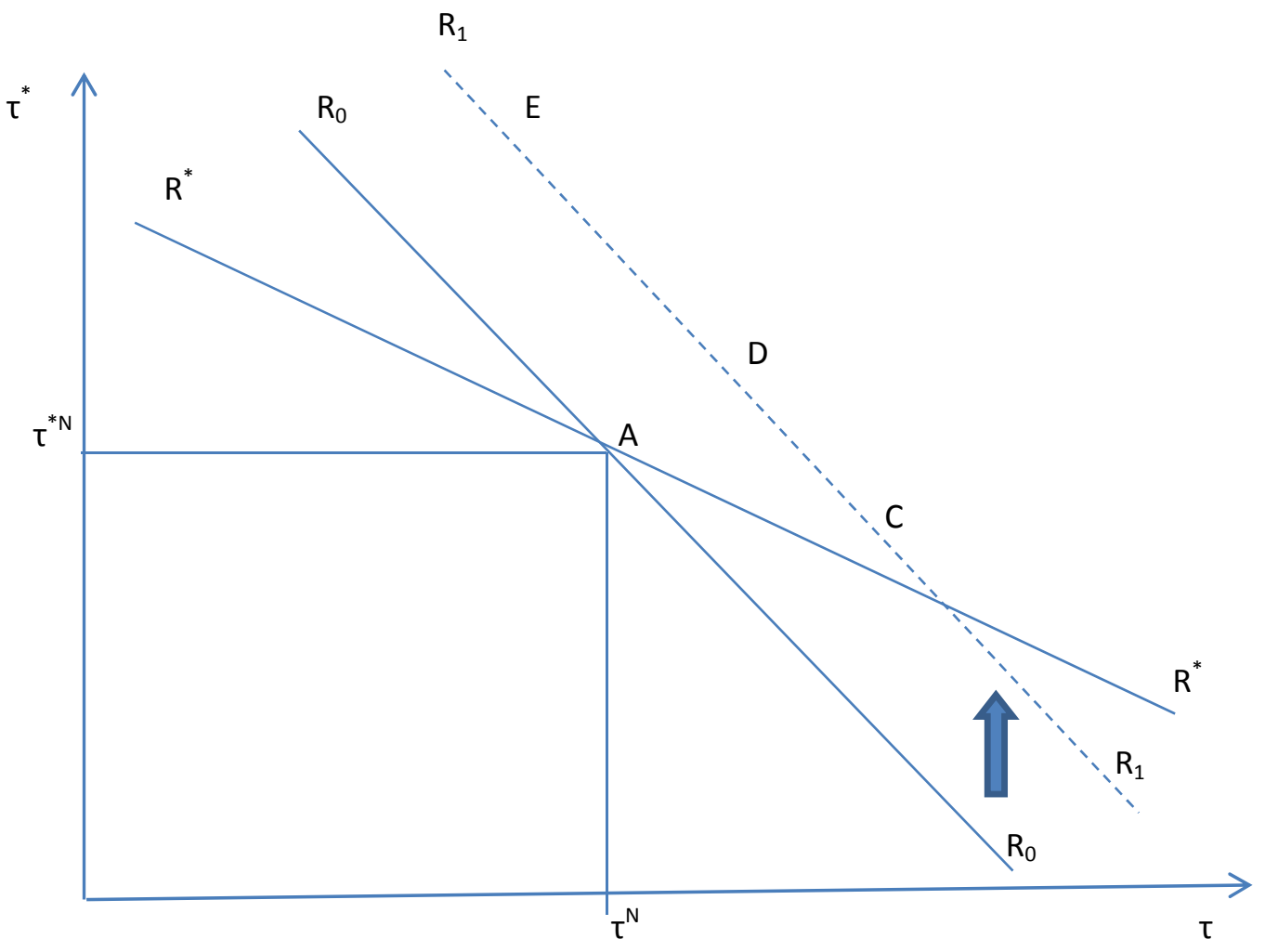

Fig. 2. Solid lines depict the initial Nash equilibrium. An increase in the pollution per unit of consumption moves upwards the Home reaction function RR. The Foreign reaction function moves also upwards and it could intersect the new Home reaction function at point $B, C$, or D. 